Ophthalmologica 1949;117:299

\title{
Spätform der Cataracta electrica
}

\section{O. \\ Knüsel}

\section{Aarau}

Ein 13 Jahre alter Knabe kletterte beim Viehhüten auf einen Mast und kam mit der Starkstroml'eitung, die 15000 Volt führte, in Berührung. Strom-eintritt am linken Arm, Stromaustritt am linken Oberschenkel (Stromaustril·ts-marke). Nach Ablauf eines Jahres erst bemerkte Pat. eine Sehstörung am linken Auge; Starextraktion drei Jahre später.

Erst sechs Jahre nach dem Unfall trat eine geringe Sehstörung am $\tau$ echten Auge auf. R. A. Visus $=0,8$, Gläser bessern nicht. Refraktion EmmetГopie. Ab-plaltung der Linse. Vordere Abschnitte klar. Feinster Asbesl'glanz der vorderen Faserung. Leichtes Farbenschill-ern der hinteren Linsenkapsel. Fasertrübungen im hinteren Abspallungsstreifen in Form von zierlichen Spitzbogen. Nur wenige Trübungen im hinteren Abspaltungstreifen halten sich nicht an praeformierte Elemente.

Wie in anderen Fallen ist das Auge auf der Körperseite des Stromein- und -austrittes frülier und intensiver erkrankt. Auffal-lend ist die lange Latenz - die ersten Sehstörungen traten 1 bzw. 6 Jahre nach dem Unfall auf - und morphologisch die Beschrän-kung der Trübungen auf den hinteren Abspaltungsstreifen.

Diskussion:

Strebel V. S. (Luzern)

bestätigt die oft sehr lange

sich über Jahre hinaus erstreckende Latenzzeit der Cataracta electrica was für Unfallentschädigungen wichtig ist. E $\gamma$ verweist auf seine díesbezügliche VeröfГentlichung hierüber in der Schweiz. M. W. 1921 Nr. 30. 